\title{
Willingness to Pay for a for a Potential Vaccine Against SARS-CoV-2 / COVID-19 Among Adult Persons
}

\section{Florian Berghea}

Universitatea de Medicina si Farmacie Carol Davila https://orcid.org/0000-0003-3405-9273

Camelia Elena Berghea ( $\sim$ bcamelia@gmail.com )

https://orcid.org/0000-0001-9522-8363

Mihai Abobului

Universitatea de Medicina si Farmacie Carol Davila

Violeta Maria Vlad

Sf. Maria Hospital, Bucharest

Research article

Keywords: SARS-CoV-2 / COVID-19, vaccine, willingness to pay, healthcare costs, health care

Posted Date: June 15th, 2020

DOI: https://doi.org/10.21203/rs.3.rs-32595/v1

License: (c) (i) This work is licensed under a Creative Commons Attribution 4.0 International License.

Read Full License 


\section{Abstract}

Background: This study aims to investigate willingness to pay for a potential vaccine against SARS-CoV2 / COVID-19 among adult persons in Romania. The study was conducted during the peak period of the pandemic curve in Europe and Romania, too.

Methods: An online survey was developed and delivered to Romanian general population by using two of the largest social networking web services (Facebook and LinkedIn). The questionnaire included demographic data, description of the responder's financial situation and their willingness to pay for a hypothetical anti COVID-19 vaccine. The study was based on the Van Westendorp Price Sensitivity Meter method.

Results: A total of 203 adult subjects participated in the survey; $42.4 \%$ male and $55,2 \%$ members of a family with at least one child. Mean participants' age was $44.12 \pm 8.9$ (mean \pm SD). The acceptable price range for a vaccine against SARS-CoV-2 / COVID-19 was situated between 20 and 200 EUR. Subgroup analyses revealed similar price range in all groups with the notable exception of those with excellent financial situation who selected a 50 to 400 EUR interval. These results match the existing optional various vaccination schemes offered in the private health care sector: $43.2 \pm 32.1$ EUR.

Conclusions: Despite substantial social impact of SARS-CoV-2, potential patients would pay for a perfect vaccination scheme against COVID-19 a price in the same range with the prices of existing vaccination schemes. Our findings could impact the way a vaccination policy will be developed in this context both in terms of general acceptance of vaccine and personal and social costs.

\section{Background}

In December 2019, a series of COVID-19 cases (a disease produced by SARS-CoV-2 coronavirus) had been identified in Wuhan (China) city; soon the disease was identified in other cities in China and then around the world. World Health Organization (WHO) declared on March 11, 2020 the pandemic level of this COVID-19 extension. As of April 12, 2020, SARS-CoV-2 produced 1.696.588 confirmed cases and 105.952 deaths in 213 countries areas and territories according WHO (1). The same day, a search on ClinicalTrials.gov (a database of private and public funded clinical studies conducted around the world) using terms "COVID-19" and "Vaccination" revealed a number of 10 active clinical trials (currently recruiting and not active yet). However no efficient vaccine or treatment was available at that date. Very tight control of social interaction (including social distancing, quarantine or self-isolation) have been imposed in more than 200 countries and territories (2) with subsequent development of various Behavioral and Emotional Disorders (3-5)

Willingness to pay (WTP) (6) is an indicator of the monetary value that people would consider paying for a product or service. In current context this term refers to the level of 'out of pocket' payments a person is ready to accept to avoid health losses or reduce health risks for themselves and their contacts. Given the communicable nature of SARS-COV-2, the impact on the responder's contacts and the "stay home" policy, 
WTP has now an additional trait, family related. A proper estimation of WTP can be used as an indicator of how much money society should be willing to spend on a vaccination program (7). WTP is related to drug characteristics (as drug's effectiveness and side effects, tolerability, convenience) and person related factors (as sex, marital status, religion, education, employment status, monthly disposable income or the patient's ability to pay) (8). However, WTP is influenced (according to economic theory) in its greatest part by the individual income (9).

\section{Methods}

\section{WTP estimation technique}

Three different methods of assessment are frequently used in pricing research: (a) direct methods that estimate consumer WTP (b) indirect methods and (c) price mix methods (10). In this study we assumed that our participants have some degree of understanding of what such vaccine is worth, so we decided to use a direct approach: the van Westendorp price sensitivity method (11).

The Van Westendorp's Price Sensitivity Meter (PSM) is widely used since its description in the 70's. The method is based on four price-related questions:

Q1- The product is too expensive: At what price would you consider the product to be so expensive that you would not consider buying it?

Q2- The product is expensive: At what price would you consider the product starting to get expensive, so that it is not out of the question, but you would have to give some thought to buying it?

Q3- The product is cheap: At what price would you consider the product to be a bargain - a great buy for the money?

Q4- The product is too cheap: At what price would you consider the product to be priced so low that you would feel the quality couldn't be very good?

The responses are then analyzed to draw a four-line graph (one for each question) and further to identify a range of acceptable prices and an optimal price point.

A WTP questionnaire was developed based on the standardized van Westendorp PSM questions; in addition, the questionnaire included consumer demographics characteristics (age, sex, education, residence, number of family members and a composite index of income and purchasing behavior). Given the rapid changing nature of perceived SARS-COV-2 threatening (new cases and new deceased reported on daily basis) the study was enrolling participants along one week only in April 2020. Emails requesting cooperation and public announcements (available on Facebook and Linkedln platforms) have been distributed manually by the authors - the subjects had the opportunity to answer voluntarily in an anonymous way by accessing the website where the questionnaire survey was conducted and by entering the answers directly on the survey form on the web. Assuming an adult population of about 16 
million (12) and a confidence level of 95\% the targeted sample was 150 people (margin of error $5-10 \%$ ). All values are presented as means \pm SD. ANOVA was used for comparisons between multiple groups followed by Tukey's post hoc test. $P<0.05$ was considered to indicate a statistically significant difference. Data was analyzed with IBM SPSS 23 and Microsoft Excel with XLSTAT adds on.

\section{Results}

\section{Demographic Characteristics}

The demographic characteristics of respondents are presented in Table 1. All participants who agreed to answer the questionnaire finalized it. The questionnaire requested 3 minutes and 15 seconds (mean value) for completion. A total number of 205 adult subjects answered. Two subjects were excluded because they offered complete unrealistic answers. Ultimately 203 responders were included in the final analysis. A composite question was used to assess responder's income and purchasing behavior $16.7 \%$ of responders declared an income large enough to allow them to eliminate tight control of money spending and $3.9 \%$ declared low income that cannot cover even the basic needs. 
Characteristics

Number (\%) TOTAL

$=203$

Sex

Male

$86(42.4)$

Female

$117(57.6)$

Education

Postgraduate

82 (40.4)

College / University diploma

$120(59.1)$

High school (12 years)

$1(0.5)$

Less than 12 years

$0(0)$

\section{Age in years}

$<45$

104 (51.2)

$>45$

99 (48.8)

\section{Residency}

In the Capital city

$127(62.6)$

In a major city

$59(29.1)$

In a minor city or rural area

$17(8.4)$

\section{Income level and purchasing behavior}

"income large enough to allow me to have anything I need without a tight control of spending"

"income large enough to allow me to have anything I need but with a tight control of spending"

"income that only covers the basic needs"

$14(6.9)$

"such a low income that cannot cover even the basic needs"

$8(3.9)$

No income

$0(0)$

\section{Size of family}

1 person (single) $39(19.2)$

2 persons

52 (25.6)

3 persons

$55(27.1)$

4 persons and more

$57(28.1)$ 
Table 1

Demographic characteristics of the respondents

As presented in Table 2 the acceptable price range of the entire group was around 20-200 EURO. The results are almost identical in all subgroup analyses with the notable exception of those with an income large enough to allow them to have anything they need without a tight control of spending; for this group WTP is about two time larger.

Table 2

Acceptable range of WTP in various subgroups

\section{Subgroup}

\begin{tabular}{ll}
\hline Entire group & $20-200$ \\
\hline Age $<45$ years & $20-200$ \\
\hline Age $>45$ years & $20-250$ \\
\hline Sex = male & $20-200$ \\
\hline Sex = female & $20-200$ \\
\hline $\begin{array}{l}\text { "income large enough to allow me to have anything I need without a tight } \\
\text { control of spending" }\end{array}$ & $50-400$ \\
\hline Any other "income" selection & $20-200$ \\
\hline Size of family = 1 person & $10-200$ \\
\hline Any other "Size of family" selection & $20-200$ \\
\hline Any "residence" selection & $20-200$ \\
\hline Any "education" selection & $20-200$
\end{tabular}

Plot of data for the van Westendorp PSM are presented in Fig. 1 for the general population. The OPP optimal price point and IPP- indifferent price point are marked. OPP is the point where an equal number of people believe a product is too cheap or too expensive. IPP - an equal number of people consider the product as cheap or as expensive. The indifference price point generally represents either the median price actually paid by consumers of the product, or the price of the product of an important market-leader (11)

\section{Discussion}

SARS-CoV-2 / COVID-19 pandemic is more and more recognized as a major health and economic issue. The infection has proven an unexpected high speed of penetration in any population followed by an important number of fatalities. The strict quarantine and social distance politics produced painful 
economic wounds in all jurisdictions that adopted them. The cost of economic healing is not yet established but for the time being about 8 trillion USD were allocated to economic proactive actions (13). Given the dual effect (health \& economic) at subjects' level, the individual motivation to get an efficient solution is probably driven by one or both dimensions of this disease. Accordingly, WTP decisions should be decrypted in relation to the environment of the responder - this environment could be protective/non protective in terms of health care. Nowadays the only considered solutions for this pandemic are vaccination and wide natural immunization. Both come with a cost - a monetary one for vaccination and a certain degree of fatalities for wide natural immunization. WTP studies are widely used to evaluate perceived benefit from vaccinations schemes. $(14,15)$ To our knowledge, this is the first study focusing on the WTP for vaccine treatment in SARS-CoV-2 / COVID-19 pandemic situation. Our data suggest an unexpected modest level of WTP for a 100\% effective and 100\% safe anti COVID-19 vaccine. Compared to the actual price of vaccination in high risk infectious areas (travel vaccination), comparable values were found: 20-200 EUR accepted for "out of the pocket" costs of a COVID-19 vaccine versus an average of 43.2 (sd:32.1) EUR in travel vaccinations schemes already offered by major networks of health services providers. As expected, the highest income group participants have a more expensive approach (WTP $50-400$ vs $20-200$ in general population). However the numbers are lower than their correspondent in cancer research - a disease acknowledged with a clear fatal course (WTP around 9000 EUR for a return in precancer health state (16) or about 2500 EUR per year for a cancer treatment (17)). Although not so strikingly different, the numbers are still lower compared to the ones in WTP studies focused on vaccination in HIV infection (220-820 EUR) (18). Consequently, SARS-CoV-2 / COVID19 seriousness is acknowledged as less important than HIV infection or cancer. However, taking into consideration that an individual protection against SARS-CoV-2 / COVID-19 (opposite to a solution for the whole population) offers the answer to a half of problem (a vaccine can protect personal health but cannot guarantee the solution of economic issues) the lower appetite for such a approach could be explained.

There were several limitations with our study. First, the estimated results in this study might be unrepresentative for the general population because of a small sample size and/or the recruitment technique (the subjects included in this exercise were recruited from those active on social networking web services). This type of study group is less represented in low educated / low income subjects. Second, none of the responding subjects suffered from SARS-CoV-2 infection, so nonresponse bias should be considered (and such an approach can provide interesting information). Third, the WTP could be influenced by the perceived ability of the local health administration to manage the pandemic. However, we consider these limitations are manageable in order to understand the value our results both in Romanian and in general European perspective.

\section{Conclusions}

Our data suggest that general population does not consider paying to avoid COVID a higher amount than what is regular paid for any vaccination. In the hypothetical case this vaccine would be available and expected to be administrated to all individuals, a higher price than the WTP interval identified in our study 
should be clearly explained to public (in order to increase the acceptance) and probably covered, at least in part, by other payers (insurance bodies, state government). In the same time other players in health services like pharma companies involved in development and production of COVID-19 vaccines, wholesalers-distributors, pharmacists and private healthcare providers should adjust their business strategies according to such information.

\section{List Of Abbreviations}

IPP- indifferent price point

OPP - optimal price point

PSM - Price Sensitivity Meter

WTP - Willingness to pay

WHO - World Health Organization

\section{Declarations}

\section{Ethics approval and consent to participate:}

The study was approved by the ethical committee of Center for the evaluation of medical technologies. All subjects agreed in written to participate in this study.

\section{Consent for publication:}

NA

\section{Availability of data and materials:}

The information generated and analyzed during the current study is available from the corresponding author on reasonable request.

\section{Competing interests:}

None

\section{Funding:}

NA 


\section{Authors' contributions:}

FB, CEB and MA conceptualized the study, designed the research and created the questionnaire. FB, MA, CEB and VV analyzed and interpreted the data. FB and VV wrote and edited the manuscript. All authors read and approved the final manuscript.

\section{Acknowledgements:}

Not applicable.

\section{References}

1. WHO. Coronavirus disease 2019 (COVID-19) Situation Report - 83 [Internet]. WHO.INT. 2020 [cited 2020 Apr 12]. Available from: https://www.who.int/emergencies/diseases/novel-coronavirus-2019

2. Travel Restrictions Covid 19, Updated Apr 10, 2020 [Internet]. TRIP.COM. [cited 2020 Apr 12]. Available from: https://www.trip.com/travel-restrictions-covid-19/

3. Xiao H, Zhang Y, Kong D, Li S, Yang N. Social Capital and Sleep Quality in Individuals Who SelfIsolated for 14 Days During the Coronavirus Disease 2019 (COVID-19) Outbreak in January 2020 in China. Med Sci Monit. 2020 Mar 20;26:e923921-1-e923921-8.

4. Jiao WY, Wang LN, Liu J, Fang SF, Jiao FY, Pettoello-Mantovani M, et al. Behavioral and Emotional Disorders in Children during the COVID-19 Epidemic. J Pediatr [Internet]. 2020 Apr 3 [cited 2020 Apr 12]; Available from: https://www.ncbi.nlm.nih.gov/pmc/articles/PMC7127630/

5. Qiu J, Shen B, Zhao M, Wang Z, Xie B, Xu Y. A nationwide survey of psychological distress among Chinese people in the COVID-19 epidemic: implications and policy recommendations. Gen Psychiatr [Internet]. 2020 Mar 6 [cited 2020 Apr 12];33(2). Available from:

https://www.ncbi.nlm.nih.gov/pmc/articles/PMC7061893/

6. Haveman RH, Weimer DL. Cost-Benefit Analysis. In: Smelser NJ, Baltes PB, editors. International Encyclopedia of the Social \& Behavioral Sciences [Internet]. Oxford: Pergamon; 2001 [cited 2020 Apr 12]. p. 2845-51. Available from:

http://www.sciencedirect.com/science/article/pii/B0080430767022397

7. Baker R, Donaldson C, Mason H, Jones-Lee M. Willingness to Pay for Health. In: Culyer AJ, editor. Encyclopedia of Health Economics [Internet]. San Diego: Elsevier; 2014 [cited 2020 Apr 12]. p. 495501. Available from: http://www.sciencedirect.com/science/article/pii/B9780123756787005034

8. Deal K, Marshall D, Dabrowski D, Charter A, Bukoski M, Moayyedi P. Assessing the Value of Symptom Relief for Patients with Gastroesophageal Reflux Disease Treatment: Willingness to Pay Using a Discrete Choice Experiment. Value in Health. 2013 Jun 1;16(4):588-98.

9. Lang H-C. Willingness to Pay for Lung Cancer Treatment. Value in Health. 2010 Sep 1;13(6):743-9. 
10. Lipovetsky S, Magnan S, Zanetti-Polzi A. Pricing Models in Marketing Research. Intelligent Information Management. 2011 Sep 20;3(5):167-74.

11. World R. A New Approach to Study Consumer Perception of Price | Research World [Internet]. 2015 [cited 2020 Apr 10]. Available from: https://www.researchworld.com/a-new-approach-to-studyconsumer-perception-of-price/

12. Recensământul populației și locuințelor 2002 | Institutul Național de Statistică [Internet]. [cited 2020 Apr 12]. Available from: https://insse.ro/cms/ro/content/recensamantul-populatiei-si-locuintelor2002

13. IMFBlog. Fiscal Policies to Contain the Damage from COVID-19 [Internet]. IMF Blog. [cited 2020 Apr 15]. Available from: https://blogs.imf.org/2020/04/15/fiscal-policies-to-contain-the-damage-fromcovid-19/

14. Adams J, Price N, Mason G. WP3 ASSESSING THE WILLINGNESS-TO-PAY (WTP) FOR INTRADERMAL INFLUENZA VACCINATION IN AUSTRALIA USING DISCRETE CHOICE METHODOLOGY. Value in Health. 2009 Oct 1;12(7):A237.

15. Harapan H, Mudatsir M, Yufika A, Nawawi Y, Wahyuniati N, Anwar S, et al. Community acceptance and willingness-to-pay for a hypothetical Zika vaccine: A cross-sectional study in Indonesia. Vaccine. 2019 Mar 7;37(11):1398-406.

16. Oh D-Y, Crawford B, Kim S-B, Chung H-C, McDonald J, Lee SY, et al. Evaluation of the willingness-topay for cancer treatment in Korean metastatic breast cancer patients: a multicenter, cross-sectional study. Asia Pac J Clin Oncol. 2012 Sep;8(3):282-91.

17. Lang H-C. Willingness to Pay for Lung Cancer Treatment. Value in Health. 2010;13(6):743-9.

18. Cameron MP, Newman PA, Roungprakhon S, Scarpa R. The marginal willingness-to-pay for attributes of a hypothetical HIV vaccine. Vaccine. 2013 Aug 12;31(36):3712-7.

\section{Figures}




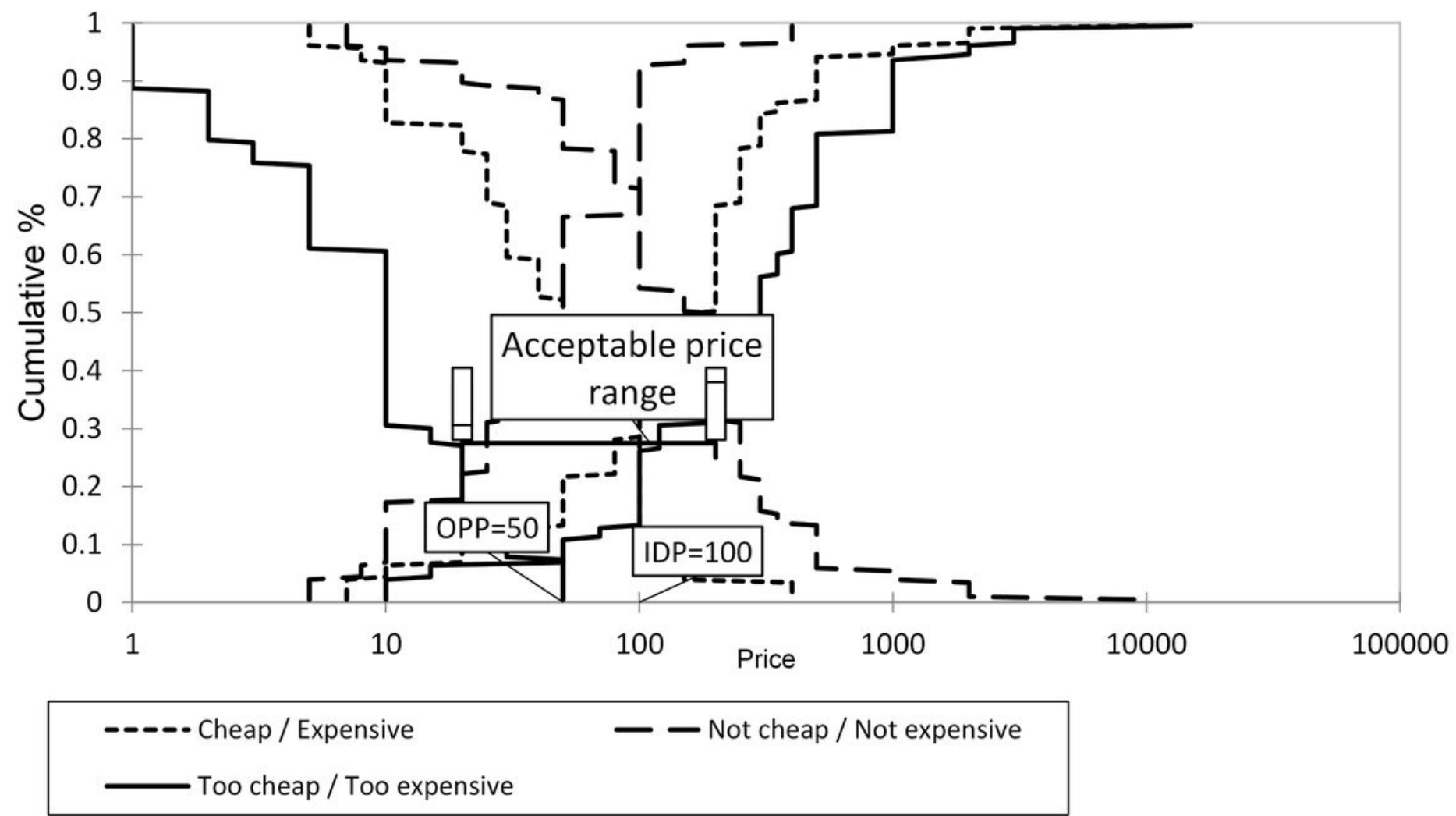

Figure 1

Plot of data for the van Westernport PSM in the whole group (Prices are in EUR) 